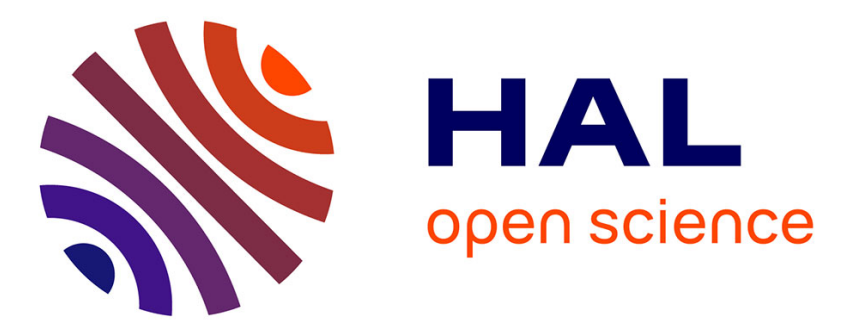

\title{
Engineering design memory for design rationale and change management toward innovation
}

\author{
Lionel Roucoules, Esma Yahia, Widad Es Soufi, Serge Tichkiewitch
}

\section{To cite this version:}

Lionel Roucoules, Esma Yahia, Widad Es Soufi, Serge Tichkiewitch. Engineering design memory for design rationale and change management toward innovation. CIRP Annals - Manufacturing Technology, 2016, 65 (1), pp.193-196. 10.1016/j.cirp.2016.04.046 . hal-01403255

\section{HAL Id: hal-01403255 \\ https://hal.science/hal-01403255}

Submitted on 25 Nov 2016

HAL is a multi-disciplinary open access archive for the deposit and dissemination of scientific research documents, whether they are published or not. The documents may come from teaching and research institutions in France or abroad, or from public or private research centers.
L'archive ouverte pluridisciplinaire HAL, est destinée au dépôt et à la diffusion de documents scientifiques de niveau recherche, publiés ou non, émanant des établissements d'enseignement et de recherche français ou étrangers, des laboratoires publics ou privés. 


\title{
Engineering design memory for design rationale and change management toward innovation
}

\author{
Lionel Roucoules ${ }^{\mathrm{a}}$, Esma Yahia ${ }^{\mathrm{a}}$, Widad Es Soufia ${ }^{\mathrm{a}}$, Serge Tichkiewitch ${ }^{\mathrm{b}}$ (1)
}

${ }^{a}$ Arts et Métiers ParisTech, CNRS, LSIS, Aix en Provence, France

${ }^{b}$ Univ. Grenoble Alpes, G-SCOP, F-38000 Grenoble, France

\begin{abstract}
As the metaphor of a film, engineering design is a process where stakeholders take decisions from product requirements to the final designed system. Unfortunately, industries lack of long term project memories to go back and forth in order to remember actions and decisions. That generates time consuming retrieval tasks that have definitively no added value since they aim at seeking past information. This paper proposes an extension of a design process meta-model that aims at tracing the project design memory. Instead of seeking past information, industries can look forward innovation and manage changes coming from new technologies, resources, KPI...
\end{abstract}

Product development, Knowledge management, Decision making

\section{Introduction to collaborative product design process}

Nowadays in a highly competitive industrial environment, companies must respond to new market demands in terms of improving quality, reducing costs, shortening time and increasing changes reactivity. Therefore enterprises must develop a comprehensive approach to master their products design phase in order to get more competitive and reactive and to save more time for innovation.

In order to meet these requirements, researchers and manufacturers, for approximately twenty years, offer to work on collaborative engineering environment to bring a large number of concepts: relations between product concepts related to function, structure or multiple views description [1], [2] and [3].

\subsection{Motivation of design rationale}

The main industrial focus concerns the product design assessment and improvement. Nevertheless, many industrial experiences highlight the difficulty to retrieve information (i.e. decision) related to previous design solutions and therefore to adapt their solutions when the industrial environment is changing. For example, it's difficult to identify how and where do industrialists have to adapt the design when dealing with improvement and innovation? And to know if a new industrialization solution is better than the previous one?

When dealing with the companies competitiveness decrease especially at the design phase, the following observations could be listed:

- Issue $\mathrm{n}^{\circ} 1$ : Time loss when engineers are seeking for the necessary information needed to finalize their design activities

In fact, various studies [4] have shown that a considerable amount of time, spent by engineers during the design phase, is dedicated to research information. A recent study of DelphiGroup [5] made with 1030 engineer from large and medium-sized companies has shown that more than $65 \%$ indicates that they spend at least $15 \%$ of their working time looking for information, and approximately $40 \%$ spend at least $25 \%$.

Thus, it is interesting to facilitate information search, in order to save this time and to exploit into innovation.

- Issue $n^{\circ} 2$ : Time loss when engineers are managing different changes

To ensure their place in the market, companies must also demonstrate capacities in identifying industrial context variations and abilities to manage changes as soon as possible in the product lifecycle and especially during the design phase. In fact, during this creative phase, it is important to master the impact of several changes that could be extremely costly if they are not properly propagated. Besides, [6] argues that $85 \%$ of the decisions made during the design phase, impact more than $80 \%$ of the product final cost so it's more interesting to deal with change during the design phase.

In consequence, the main research objectives consist in mastering choices (i.e. decisions), taking by different stakeholders during the design and manufacturing phases and tracing them in order to infer knowledge and facilitating decisions. This will lead to the reduction of non-value added activities (i.e. lean design) as searching information, repeating mistakes, reinventing solutions...

\section{Orientation of the proposal and questions of research:} decision making in product design process

Modelling the design rationale could answer the above research objectives. In fact, the authors assumed that it is important firstly, to trace how designer made choices during the design process and secondly, to reuse some pattern of the choice process in their future design processes. Besides, the authors assume that tracing and capitalizing the decision making will reduce the time loss for information retrieval and information exchange. Thus, the designers will have more time for innovation.

The scientific community has already dealt with Design rationale [7], [8] and so far, many representations have been 
proposed by [9]. This paper aims at identifying the main design rationale concepts and implementing them based on the Six W's (who, what, why, where, when and how) conceptual model [10]. By capturing those concepts during the collaborative design phase, the authors assume that information retrieval and change management will be faster. Therefore, in order to achieve the research objectives, the authors propose to answer to the following research functions:

- F1: How to model collaborative design information based on Six W's: who takes a decision, what is the decided information, when and where the decision has been taken, how and why the decision has been taken? The capitalizing of those concepts reduces the time of information retrieval

- F2: How to trace design rationale and capitalize learning processes. Those learnt situation will be used on future situations.

Figures 1 describes the global view of each questions of research in order to support decision making in engineering design. The authors assume that when the design is complex, several decisions have to be taken since all the solutions cannot be assessed and considered:

- Initial design space which is mastered using knowledge modelling that constrains the admissible solutions. Those constraints are related to the design context.

- Assessment of each admissible solution in the performance space.

- $\quad$ Final decision making using multi-criteria analysis.

- One decision, with respect to specific parameters, can be propagated to another decision making activity, etc.

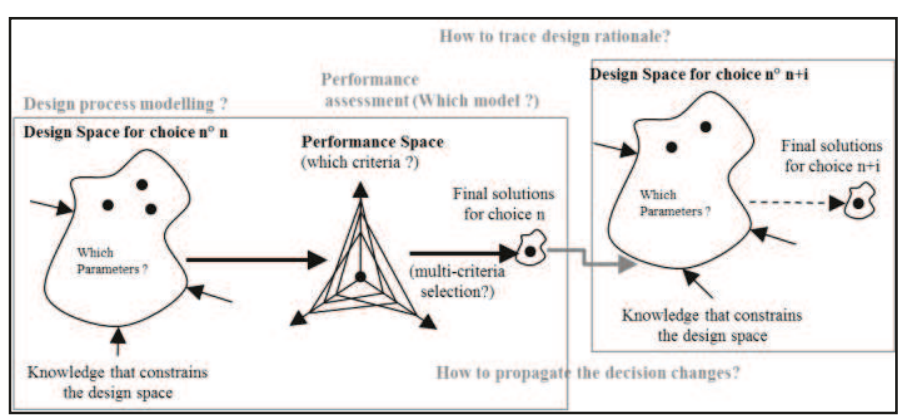

Figure 1. Overview of decision making and main research questions of the proposal

\section{Background Literature}

Within the collaborative engineering product development cycle, the design process is considered as a creative process since it is not known only when the design starts [11]. It is a high added value process regarding its complexity and the various business expertises which are involved under a collaborative context with different specificities, actors and organizations. This creative process is also a dynamic process as it is adjusted and adapted frequently during its execution when answering to the recurrent modification demands. In order to master this creative and dynamic process, it is primordial to emphasize on a nonfunctional feature [11] which is the traceability.

In this section, we aim, at first, to define traceability and its objectives in the context of product design process and then to make a state of the art of the different traceability approaches.

\subsection{Product Design Decision Traceability}

The concept of traceability evolved in different engineering context among computer science and product development. It refers to the action to follow or mark something (oxford dictionary). In the context of Product development process, traceability is the action to collect the diverse events occurring during the execution of a given process. It aims to record the process lifecycle history by capturing:

- The design routes and the evolution of design items [12].

- The information relative to the product and the process as well as their relations in the various product lifecycle phases [13]

- The important decisions and justification during the process lifecycle [13]

- The diverse modifications that took place during the conception process lifecycle

According to [14], traces are then used to (a) understand lessons from previous experiences and to (b) reuse the "captured design knowledge to adapt past solution and apply them to current and future problems". This design knowledge is captured with respect to different design decision-making frameworks proposed by [15], [13] which are adapted from the Zachman framework [10]. The latter, structures the holistic enterprise mechanisms representation by answering to the basic communication interrogatives: Six W's.

The meta-model for achieving traceability proposed by [15] and [13] have been analysed as:

- What represents the design objects that correspond to I/O of the design process; it could correspond to requirements, technologies, functions, parts...

- Who corresponds to the actors with different competencies that are creating and using the design object.

- How and Where represent the 'sources' that documents the design objects between numerical documents, procedures and with different format types and formalization levels.

- When represents two 'time dimensions' related to the design object: the relative time that corresponds to the order of execution and the absolute time that corresponds to the version, state and the stage of the design object.

- Why represents the design rationale behind the creation, evolution and changing of the design. It corresponds to the decisions made and justified by the actors, which affect the selection and the evaluation of the design objects.

\subsection{A comparison of different traceability approaches}

Several researchers have proposed different approaches to capture and trace the design experience knowledge and to exploit, dynamically, those traceability constructs to infer some knowledge rules. The traces are supposed to facilitate the understanding of the design activities and their analyses by visualizing the "captured knowledge" [16] in order to evaluate the process performance and to detect the frequent sequences, delays and the eventual conflicts ...

The MUSETTE approach developed by [17], in the context of computer system use, exploits the interaction traces between the systems and its users in order to assist the Agent- Task Management. The approach, developed by [18], aims to retrieve necessary and useful activities supervision information for the users involved in a context of Computer Learning Environments with heterogeneous tools. Besides, [19] exploit the traces, in the context of collaborative process, to improve the communication between users and to contribute to the establishing of a common knowledge. Moreover, [20] approach aims to specify and elaborate a knowledge oriented maintenance platform by exploiting the traceability constructs under the SBT (System Based on Traces) proposed by [21].

Despite their different contexts of use, the studied traceability approaches are mainly articulated around three major connected 
phases: (a) traceability constructs collection based on the design process observation, (b) traces generation with respect to the objective of use and (c) traces visualization and exploitation.

\subsection{Process modelling for Design Rationale}

Companies are recognizing that process modelling is a higher priority as there is an increasing need to document, understand and improve their business processes. Indeed, process modelling helps the organization [22]:

- $\quad$ Capture and formalize existing processes to understand how they work

- Create a baseline for potential improvements and redesign such us reducing inefficiencies, meet customer requests and respond faster to them.

- Design future processes with these improvements incorporated in order to gain in competitiveness

In our context, the objective of process modelling is to capture design knowledge based on the constructs of Zachman's framework; the Six W's: Who did What, When, How, Where and Why [10]. This allows retrieving this information at any future time. For this, we need to:

- Define a meta-model that identifies this information

- Define a modelling language that allows capturing the concepts presented in the meta-model.

\section{Discussion of the state of the art and proposal overview}

In order to trace the process rationale in the context of collaborative design, authors propose a framework based on the three-layer traceability approach (figure 2).

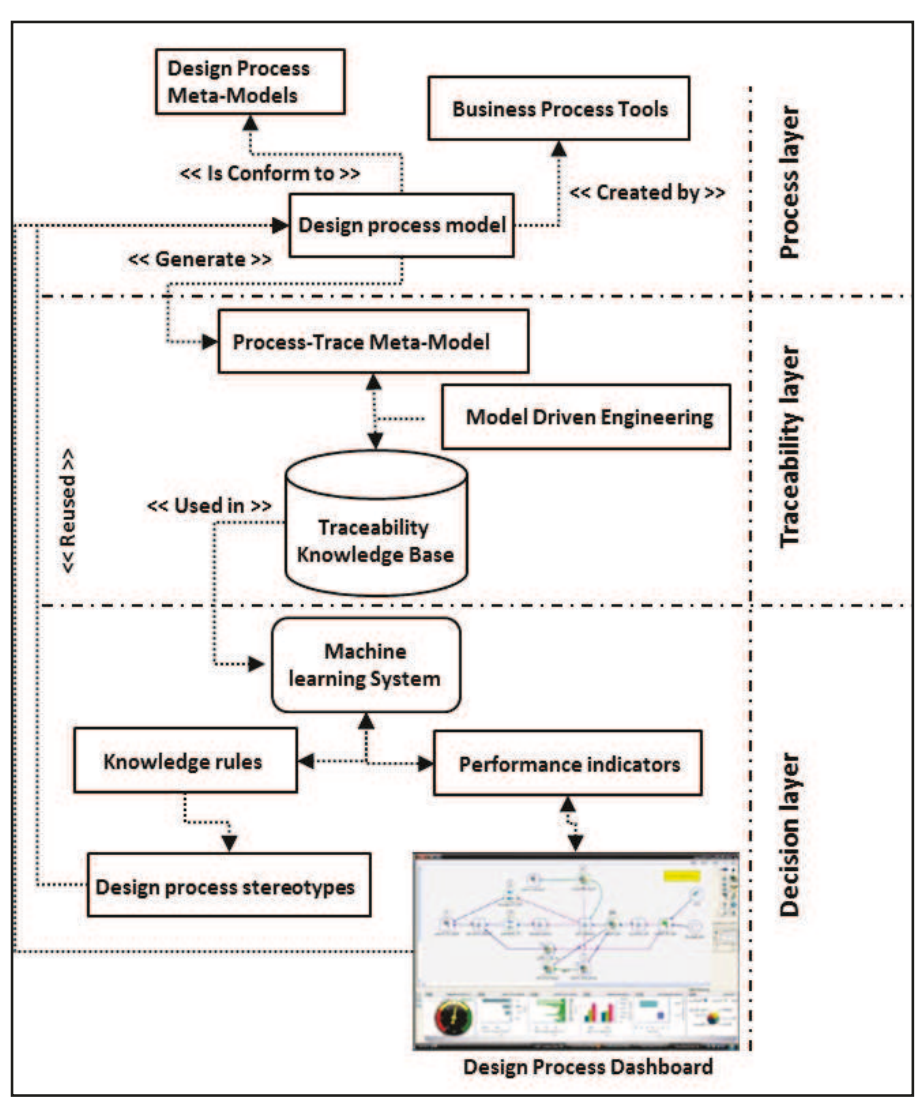

Figure 2. Overview of the proposal

\subsection{Framework Process Layer}

This layer depicts the phase of the design process. Therefore, we need to: (i) identify a business process meta-model allowing to describe the information to which we are interested in the design process model, (ii) model the design process using one of the existing businesses modelling language. Thus, this layer helps us have a clear vision of the design process itself.

Authors have identified different use case that occurs when dealing with the design process as a creative set of activities. The user start by creating the process then he defines the activities. Thus, depending of the context of his process creation, the user defines a design activity (modelling activity or a decision activity) or a control activity, the figure depicts all the possible use cases:

- The design activity is a creative activity that produces an added value it is considered as:

- a modelling activity when it is an activity that transform the input into outputs and this by taking on consideration some constraints and based on some resource

- a decision activity that consist on selecting a design solution from the sets of admissible solutions

- The control activity consists on assuring industrial process diagnostic. In our context, we define the activity of control as a decision activity that need: an instruction to express the desired result of the activity and a result of supervision coming from an activity of supervision. The activity of control generates decisions by analysing the result of the supervision with regard to the instruction

Figure 3 shows in UML formalism the design rationale model describing all the constructs that contribute to the creation of product knowledge during the design phase.

This meta-model was implemented in Eclipse environment. Based on this model, a Java interface (Figure 4) has also been created in order to facilitate the edition of process model constructs.

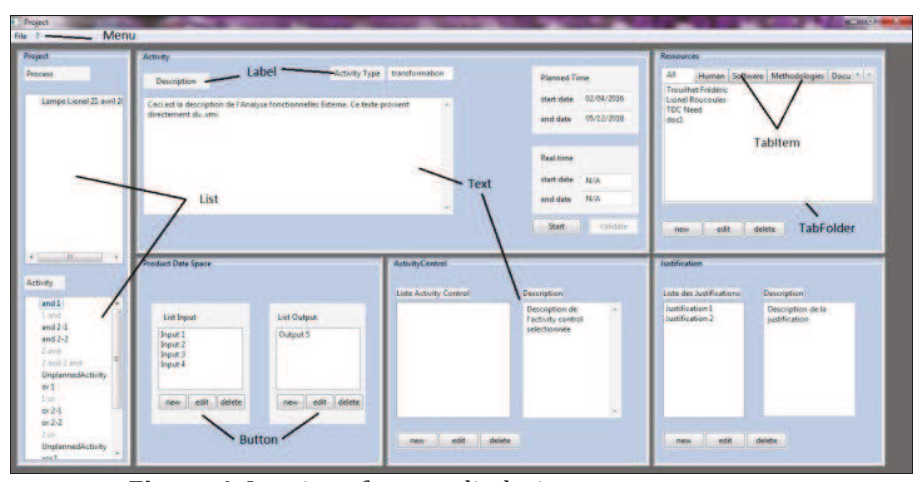

Figure 4. Java interface to edit design process concept

\subsection{Framework traceability Layer}

The challenge of this layer is to identify the process trace constructs in order to build the traceability knowledge base. The authors assume that the trace process model corresponds to all the knowledge constructs identified under the process design model and to all the constructs related to the workflow execution such as the real time process start and end.

This traceability model was implemented under the Eclipse environment in order to derive automatically an Excel table that could be exploited in the framework decision layer to establish the performance keys. 


\subsection{Framework decision Layer}

This layer corresponds to the exploitation and reuse of the collected traces. It consists of two parts:

- Performance key generation and process design dashboard.
- $\quad$ Design rules deduction using machine learning. Those rules could be used automatically by the software resources in the design process or by the actors themselves and this according to their experiences feedbacks

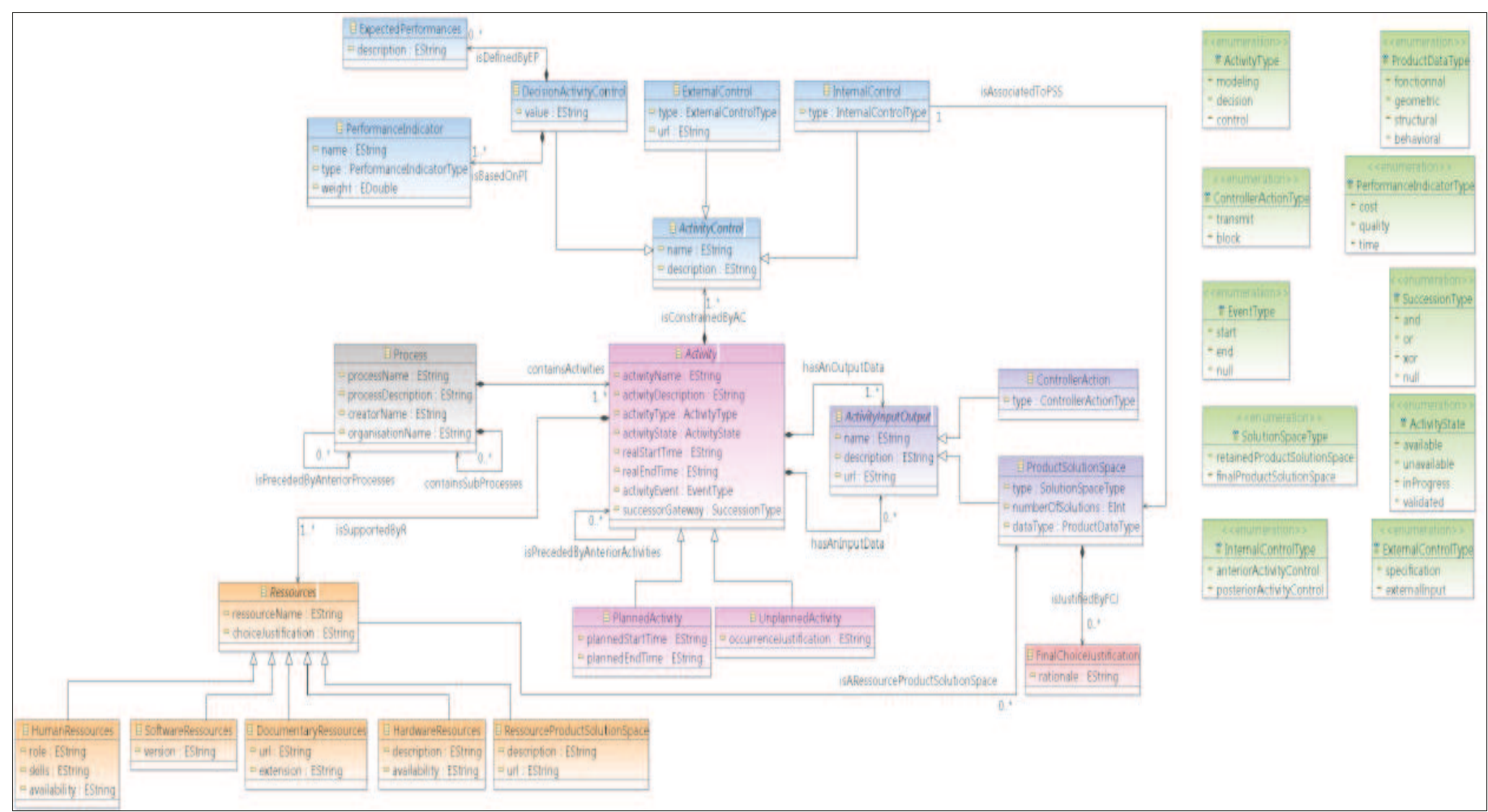

Figure 3. Proposed UML formalism to identify knowledge construct for design rationale

\section{Conclusions and future works}

This paper proposes a traceability model based on design rationale capture. This allows modelling the Six W's concepts, supporting the design change identification and tracing the decision making. The three-layer traceability approach is currently partly implemented (process modelling, trace modelling).

Future works will consist in deploying design example and to couple the two first layers with learning approach in order to support decision making based on capitalized design situation. Those examples will also be benchmarked with current approach in order to validate all the assumptions of this work:

- Accelerate information retrieval

- Accelerate change propagation

- $\quad$ Support decision making and alternatives performances assessment

\section{References}

[1] Gero, J. S., 1990. , Design prototypes: a knowledge representation schema for design. AI Magazine, 11(4), pp. 26--3.

[2] Krause, F., Kimura, F., T., K. \& Lu S.C, P., 1993. Product Modelling. Annals of the CIRP, 42(2).

[3] Noël F., Brissaud D., Tichkiewitch S., 2003, Integrative Design Environment to Improve Collaboration between Various Experts. CIRP Annals - Manufacturing Technology, Volume 52, Issue 1, Pages 109-112.

[4] Ullman, D., 2003, The mechanical design process. 3 rd éd. McGraw-Hill.

[5] DelphiGroup, 2011, The High Cost of Knowledge :A Look at the Impact of the Global Economy on Knowledge Work, Employment and Organizations, http://www.eccentex.com/pdfs/wp_delphi_grp_knowledge_work.pdf.

[6] Berliner C. \& Brimson J.A., 1998, Cost management for today's advanced manufacturing. The CAM-I. conceptual Design, Harvard Business School Press.
[7] Jin Y., Lu S.C, 1998, An Agent-Supported Approach to collaborative Design, CIRP Annals.

[8] Lutters D., Vaneker T.H.J.,. van Houten F.J.A.M, 2004, 'What-if' design: a synthesis method in the design process, Annals of the CIRP, 53 (1).

[9] Hu X., Pang J., Pang Y., Atwood M., Sun W., Science, C., \& Regli, W. C., 2000, A survey on design rationale: representation, capture and retrieval. In ASME Design Engineering Technical Conferences.

[10] Zachman J. A., 1987, A Framework for Information Systems Architecture,. IBM Systems Journal. 26(3). 276-292.

[11] Godard C. \& Perrin O., 2004, A model to support collaborative work in virtual enterprises. In Data and Knowledge Engineering, Elsevier, vol. 50, n¹, pp. 63--86.

[12] Storga M., 2004, Traceability in product development. International design conference - DESIGN 2004, May 18 - 21, Dubrovnik.

[13] Ouertani M., Baina S., Gzara L., Morel G., 2011, Traceability and management of dispersed product knowledge during design and manufacturing. Computer-Aided Design, May, 43(5), pp. 546-562.

[14] Ahmed S., 2005, Encouraging reuse of design knowledge: a method to index knowledge. Design Studies, 26(6), pp. 565--592.

[15] Hansen C., Andreasen M., 2000, Basic thinkings patterns of decision-making in engineering design. MCE 2000 International Conference on Multi-Criteria Evaluation Neukirchen (Germany)., pp. 1-8.

[16] Moones E., YAHIA E., Roucoules, L., 2014, Design process and trace modelling for design rationale capture. Proceedings of the joint Conference on Mechanical, Design Engineering and Advanced Manufacturing, Toulouse.

[17] Champin P., Prié Y., Mille A., 2003, Musette: Modelling uses and tasks for tracing experience. ICCBR, Volume 3, pp. 279--286.

[18] Broisin J., Vidal P., Duval E., 2005, A Model driven Approach for the Management of Learning Objects' Usage. Proceedings of Intelligent, Interactive, Learning Object Repositories Network, LORNET Research Network, Vancouver

[19] Pavkovic N., Storga M., Bojcetic N., Marjanovic D., 2013, Facilitating design communication through engineering information traceability. Artificial Intelligence for Engineering Design, Analysis and Manufacturing, 27(2), pp. 105--119.

[20] Karray M.-H., Chebel-Morello B., Zerhouni N., 2013, A Trace based system for decision activities in CBM Process. 14th IFAC Symposium on Information Control Problems in Manufacturing, INCOM'12., May 2012, Bucharest, Romania, pp 1-6.

[21] Settouti L., Prie Y., Marty J., Mille, A., 2009, A trace-based system for technologyenhanced learning systems personalisation. Proceedings of the Ninth IEEE International Conference on Advanced Learning Technologies, ICALT 2009, Riga .IEEE, pp. 93 - 97.

[22] Havey M., 2005, Essential Business Process Modelling. O'Reilly Media. 